\title{
CORRECTION
}

\section{Opioid-associated amnestic syndrome observed with fentanyl patch use}

CMAJ has been made aware of an error that occurred in the Mar. 25, 2019, issue. ${ }^{1}$

In the first paragraph of the article, the third sentence read, "Her usual daily medications included hydromorphone $9 \mathrm{mg} 3$ times per day, zopiclone $7.5 \mathrm{mg}$ every night at bedtime and pregabalin $75 \mathrm{mg}$ twice per day, all of which had been taken at the same dose at which they had been used for the last year." This should have read, "Her usual daily medications included hydromorphone $9 \mathrm{mg} 3$ times per day, zopiclone $7.5 \mathrm{mg}$ every night at bedtime and pregabalin $75 \mathrm{mg}$ twice per day, all of which had been taken at the same dose at which they had been used for the last year, except for the hydromorphone. In the weeks before her presentation to hospital, the patient had not been taking her hydromorphone as prescribed because of adverse effects."

This has been corrected at cmaj.ca.

- Cite as: CMAJ 2019 November 4;191:

E1228. doi: 10.1503/cmaj.191311

\section{Reference}

1. Taylor RG, Budhram A, Lee DH, et al. Opioidassociated amnestic syndrome observed with fentanyl patch use. CMAJ 2019;191:E337-9. 